\title{
THE USE OF LATERAL ACCESS TO THE HIP JOINT FOR ENDOPROSTHETICS
}

\author{
Leonova S.N. ${ }^{1}$, Grishchuk A.N. ${ }^{1}$ \\ ${ }^{1}$ Irkutsk Scientific Centre of Surgery and Traumatology, Irkutsk, e-mail: svetlana.leonova.1963@mail.ru
}

Aims.

The aim of the study is the development of lateral access to the hip joint when performing endoprosthetics in patients with 3rd stage protrusion coxarthrosis

Materials and Methods.

Endoprosthetics of the hip was performed in 44 patients with 3rd stage protrusion coxarthrosis, complicated by signification ossification of the edges of the acetabulum and its lip. Mean patient age $-60 \pm 1.5$ years old Women comprised 63.6\% Surgical approach to the hip according to the Hardinge method (K. Hardinge) was used in 29 patients; 15 patients were operated using the modified lateral access.

Results.

A comparison analysis of the use of lateral access to the hip for endoprosthetics was conducted. It has been proven that access as per Hardinge is more trauma-inducing because this damage a larger amount of muscles, which delays the process of the recovery of the function of the operated extremity and can be the causing factor for infectious complications. The greater area of access during surgery with access as per Hardinge has a negative effect on the recovery of the function of the operated hip. In the modified lateral access, universal guide marks were used in the projection of the greater trochanter, which allow for the most precise initial points of the performed incisions to be found and for the ligament-muscular sheet of the gluteus medius muscle to be formed correctly. Creating a central line and marking the edges of the proximal, medial, and distal parts of the greater trochanter makes it possible to precisely perform three incisions on the gluteus medius muscle. It was determined that, by the 7 th day after the surgery, a significant difference in the function of the operated hip was evident, which was much worse with access as per Hardinge than with the use of modified lateral access.

Conclusions.

Modified lateral access to the hip is less trauma-inducing, more physiological, prevents ruptures and separation of muscle fibres, favours faster repair of surrounding muscle and the functional condition of the operated hip, and decreases the risk of infectious complications.

Key words: lateral access, hip, endoprosthetics.

\section{INTRODUCTION.}

Hip joint replacement (HJR) is performed by different surgical approaches. Primarily, anterolateral and posterolateral approaches are used. In patients with severe pathology of the hip joint (severe degree of coxarthrosis, expressed ossification of the edges of the acetabulum and acetabular labrum, protrusion of the femoral head), few approaches can be used during endoprosthetics. The search for the optimum approach to the hip joint requires the analysis of its drawbacks. The benefits and drawbacks of the anterior and posterior approaches to the hip joint are widely described in the published literature [1-3].

The study was aimed to analyze the results of the application of lateral approaches to the hip joint during HJR.

\section{MATERIALS AND METHODS.}

The study was based on the analysis of the results of surgeries performed by the authors using lateral approaches during hip joint replacement in 44 patients with 3rd-degree protrusion coxarthrosis complicated by the expressed ossification of the edges and labrum of the acetabulum.

The mean age of patients was $60 \pm 1.5$ years old. There were $63.6 \%$ of women in the study.

All the patients underwent the required laboratory and clinical-instrumental studies.

Two lateral approaches to the hip joint were used in this complicated clinical situation: the 
Hardinge approach and the proposed modified lateral access. In all patients, HJR was performed with an ESI endoprosthesis.

A direct lateral access proposed by Bauer and modified by Hardinge includes a $12-16 \mathrm{~cm}$ skin dissection anterior to the greater trochanter, dissection of the broad fascia along the operative wound, separation of the fibers of the gluteus medius muscle along $3 \mathrm{~cm}$ anterior to the greater trochanter, subperiosteal separation of the gluteus medius muscle and the lateral portion of the quadriceps muscle of the thigh from the anterior surface of the greater trochanter. Further, a dislocation of the femoral head is performed followed by the other surgical manipulations $[3,4]$.

The modified lateral approach to the hip joint includes the following stages: skin dissection in the projection of the greater trochanter, dissection of the broad fascia, and the performance of three incisions. The first 3-cm-long incision is made from the proximal point along the fibers of the gluteus medius muscle in the anterosuperior direction. The second 3-cm-long incision is made anteriorly from the point on the borderline between the median and distal third of the greater trochanter $1 \mathrm{~cm}$ from the central line. The third incision is made by a bow-like connection (convex anteriorly) of the initial points of the first and second incisions (Figure 1). The gluteus medius muscle is dissected from the anterior surface of the greater trochanter within the performed incisions. The obtained flap of the gluteus medius muscle is moved anteriorly and fixed with surgical instruments. Further, a dislocation of the femoral head and hip joint replacement are performed. After the main step, the anteriorly moved muscular-tendon flap is placed back and fixed with sutures [5].

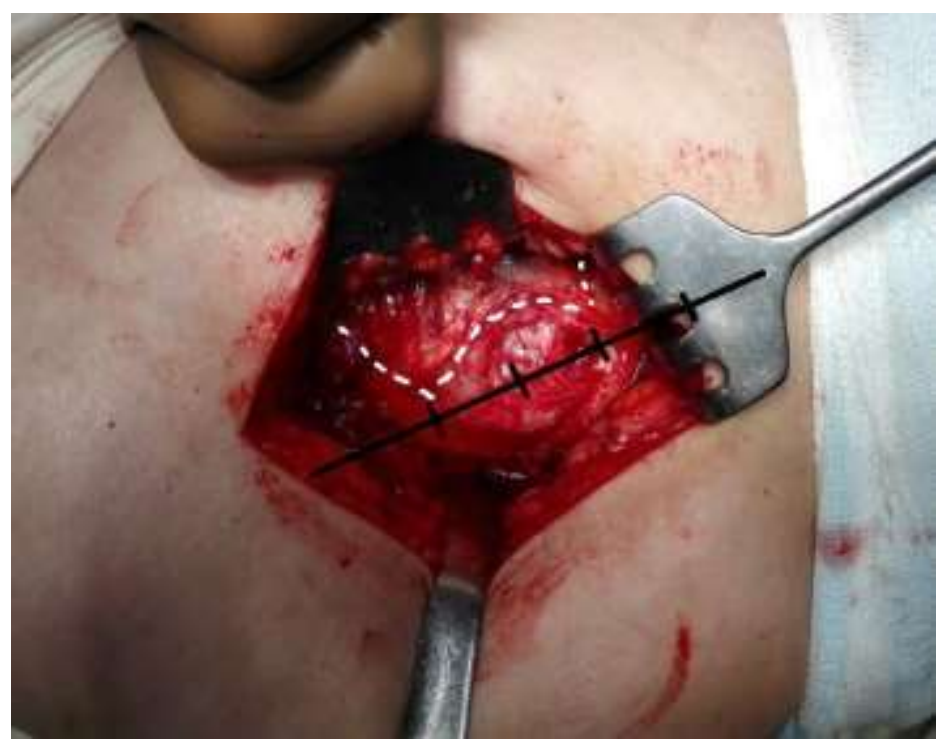

Figure 1. The scheme of the modified lateral approach to the hip joint in Patient L: three incisions are marked to be performed on the gluteus medius muscle for the formation of a flap (intraoperative picture).

Statistical processing of the obtained results was performed with the Statistica 8.0 software. The comparative analysis of the obtained data between the groups was performed with the nonparametric Mann-Whitney test. The differences were significant at $p<0.05$. 
The present study was approved by the local ethical committee. The aim and methods were explained to the participants who signed the form of the informed consent for the examination, treatment, and publication of the obtained data.

RESULTS. The Hardinge approach during HJR was used for 29 patients with 3rd-degree protrusion coxarthrosis (Group I). The modified lateral approach was used in 15 patients with 3rddegree protrusion coxarthrosis (Group II).

The evaluation of the results of the application of these surgical approaches to the hip joint included intraoperative and postoperative hemorrhage, intraoperative visualization of the hip joint, intraoperative muscle strain and rupture, and functional results by the Harris scale [6].

The analysis of the obtained results showed that intraoperative visualization was sufficient in both groups. No strains and ruptures were registered during the stages of HJR.

The analysis of blood loss revealed that in patients from Group I (Hardinge approach), the volume of intraoperative and postoperative hemorrhage was significantly higher than in patients from Group II (Table 1).

Table 1. The criteria of the effectiveness evaluation of the lateral access to the hip joint during HJR in patients with protrusion coxarthrosis $(M \pm m)$

\begin{tabular}{|c|c|c|c|c|}
\hline \multirow[t]{2}{*}{ No. } & \multirow[b]{2}{*}{$\begin{array}{l}\text { Criteria of the } \\
\text { effectiveness } \\
\text { evaluation }\end{array}$} & \multicolumn{2}{|c|}{$\begin{array}{l}\text { Groups of patients with } 3 \text { rd-degree } \\
\text { protrusion coxarthrosis }(n=44)\end{array}$} & \multirow[b]{2}{*}{$\mathrm{p}$} \\
\hline & & $\begin{array}{l}\text { Group } 1 \text {, the Hardinge } \\
\text { approach }(n=29)\end{array}$ & $\begin{array}{l}\text { Group 2, modified } \\
\text { approach }(n=15)\end{array}$ & \\
\hline 1. & $\begin{array}{c}\text { Intraoperative } \\
\text { hemorrhage }(\mathrm{ml})\end{array}$ & $241.67 \pm 12.34$ & $208.33 \pm 9.72$ & $\mathrm{p}<0.05$ \\
\hline 2. & $\begin{array}{c}\text { Postoperative } \\
\text { hemorrhage }(\mathrm{ml})\end{array}$ & $318.33 \pm 15.41$ & $83.33 \pm 11.96$ & $\mathrm{p}<0.01$ \\
\hline 3. & $\begin{array}{c}\text { Intra-operational } \\
\text { visualization of the } \\
\text { hip joint }\end{array}$ & sufficient & sufficient & \\
\hline 4. & $\begin{array}{l}\text { Intra-operational } \\
\text { muscle strain and } \\
\text { rupture }\end{array}$ & no & no & \\
\hline 5. & $\begin{array}{c}\text { Functional result on } \\
\text { Day } 7 \text { after the } \\
\text { surgery (points) }\end{array}$ & $55.5 \pm 1.26$ & $69.17 \pm 1.4$ & $\mathrm{p}<0.01$ \\
\hline
\end{tabular}

The examination of patients by the Harris scale performed on Day 7 after the surgery showed that the functional result in Group I was significantly lower. The obtained results allowed the authors to establish that on Day 7 after the surgery, there was a significant difference in the functional condition of the operated hip joint, which was significantly lower in cases when the Hardinge approach was used (Table 1).

In patients from Group II with the modified lateral approach to the hip joint, the wound was 
healed by the primary intention. There were no infectious complications registered during the follow-up year observation. The patients were satisfied with the functional result and did not have pain syndrome in the hip joint.

Out of 29 patients from Group I, wherein the Hardinge approach was used, five patients had sanioserous-hemorrhagic discharge after the drainage removal and the post-operative wounds healed longer. Seven patients had follow-up examination and conservative treatment for periodic pain syndrome in the operated hip joint during the year. At the same time, two patients received conservative treatment for latent infection in the area of the endoprosthesis. In three patients, there was a motion restriction in the joint and limp. These patients were not satisfied with the functional result of HJR.

DISCUSSION. The analysis of the obtained results and available published data allowed the authors to identify the benefits and drawbacks of lateral approaches to the hip joint during HJR.

It is possible to use the Muller approach for HJR, which involves the dissection of the anterosuperior myotendinous portion of the gluteus medius muscle [3]. However, in patients with protrusive coxarthrosis with expressed ossification of the edges and labium of the acetabulum, the authors did not use this approach because, in this case, it was impossible to perform HJP without complications. The L-like Muller approach does not provide sufficient visualization of the hip joint and limits the area of surgical manipulations, which requires additional tissue extension and leads to the traumatization of the operative wound. Spearing of the anteroinferior portion of the gluteus medius muscle tendon (Muller approach) creates certain difficulties at different stages of HJR. Additional effort and techniques are required at the stage of femoral head dislocation, during the preparation of the acetabulum, and the repositioning of the endoprosthesis head, which leads to overextension, strain, and ruptures. Strains and ruptures from the gluteus medius muscle, as well as the rupture of the bone plate of the greater trochanter, lead to the dysfunction of the gluteus medius muscle, limp, and lack of the limb active abduction.

Additional traumatization of tissues negatively influences joint functioning and increases the risk of infectious complications because it leads to blood circulation impairment, the formation of soft-tissue cavities, tissue necrosis, and infection development.

The Hardinge approach was shown to be less effective during HJR in comparison with its modified lateral approach, which was characterized by a greater volume of blood loss, significantly poorer functional result, pain syndrome, and infectious complications in the operated joint. Apart from the dissection of the gluteus medius, the Hardinge approach to the hip joint includes the dissection of the lateral portion of the quadriceps muscle and its vessels, which makes this approach more traumatic for the muscles that cover the hip joint. An increase in the injury rate of the approach provides an increase in the volume of the intraoperative and postoperative blood loss. In turn, an increase in blood loss increases the risk of anemia, immune insufficiency, and complications associated with postoperative wound healing. The Hardinge approach during HJR is 
characterized by a high risk of infectious complications. Possible infecting of the operative wound (Hardinge approach) is associated with vast muscle tissue and vessel injury. A longer incision that damages more muscles during the surgery (Hardinge approach) negatively influences the regenerative functions of the operated hip joint and limb.

The analysis of the results of HJR with lateral approaches allowed the authors to identify the benefits of the modified approach that include certain technical manipulations.

The modified lateral approach involves universal markings in the projection of the greater trochanter that allow for more precise identification of initial points for the incisions and formation of a myotendinous flap of the gluteus medius muscle. The central line and the marking of the borders of the proximal, medial and distal parts of the greater trochanter provide the layout for three incisions on the gluteus medius muscle. The first incision, which is $3 \mathrm{~cm}$ long and is performed along the muscular fibers of the gluteus medius muscle anterosuperior from the proximal border of the greater trochanter, prevents the stain of the fibers of the gluteus medius muscle from the greater trochanter, decreases the traumatization of the gluteus medius muscle and the greater trochanter during the dislocation of the femoral head and installation of the femoral component of the endoprosthesis. Due to the second incision, which starts on the border between the medial and distal parts of the greater trochanter and continues for $3 \mathrm{~cm}$ anterior without damaging the fibers of the lateral portion of the quadriceps muscle, the anteroinferior portion of the gluteus medius muscle does not get strained from the greater trochanter at the stage of the femoral head dislocation and during the treatment of the acetabulum. The third incision (bow-like), performed between the first and the second ones, allows the surgeons to preserve the tendon cuff of the gluteus medius muscle on the greater trochanter, which contributes to anatomic and functional restoration of this muscle. The formation of a mobile myotendinous flap with smooth edges within the performed incisions prevents the strain and ruptures of muscular fibers, dysfunction of the gluteus medius and hip joint, limp, and restraint of the lower limb active abduction. The anterior disposition of the myotendinous flap of the gluteus medius muscle increases the area of visualization of the operative field and surgical manipulations during HJR. Smooth edges of the flap are easily placed back and fixed with sutures along the incisions.

The modified lateral access to the hip joint during HJR appears to be less traumatic due to the formation of a mobile myotendinous flap from the gluteus medius. This approach is also more physiological, prevents strains and rupture of muscular fibers, increases the area of visualization of the operative field and surgical manipulations during HJR, contributes to faster regeneration of the surrounding muscular tissue and the functional status of the operated hip joint, and reduces the risk of infectious complications.

\section{CONCLUSIONS.}

A comparative analysis of the lateral approaches to the hip joint during HJR allowed the authors to reveal their drawbacks. The Muller access leads to overextension, strain, and rupture of 
the gluteus medius muscle, which negatively influences the joint functioning and increases the risk of infectious complications. The Hardinge approach is more traumatic because of the damage of more muscles during the surgery, which slows down the process of restoration of functioning of the operated limb and can cause infectious complications.

The modified lateral approach to the hip allows the surgeons to avoid the drawbacks of the Muller and Hardinge approaches dues to the formation of a mobile myotendinous flap from the gluteus medius muscle.

\section{FINANCIAL SUPPORT AND SPONSORSHIP}

Nil.

\section{CONFLICTS OF INTEREST}

The authors declare no conflict of interest

SUPPLEMENTARY DATA (DOI)

\section{REFERENCES}

1. Andreev D.V. Total hip arthroplasty using a minimally invasive technique: dissertation of candidates of medical sciences. [Total'noe endoprotezirovanie tazobedrennogo sustava $\mathrm{s}$ ispol'zovaniem maloinvazivnoi tekhniki: dissertatsiia kandidata meditsinskikh nauk]. St. Petersburg, 2013, 196 p.

2. Prokhorenko V.M., Turkov P.S. Effect of the position of the proximal femoral part on the choice of operative access [Vliianie polozheniia proksimal'nogo otdela bedrennoi kosti na vybor operativnogo dostupa]. Medicine and education in Siberia - Meditsina i obrazovanie v Sibiri, 2013, no. 3, p. 21.

3. Tikhilov R.M., Shapovalov V.M. Hip endoprosthesis guide. [Rukovodstvo po endoprotezirovaniiu tazobedrennogo sustava]. St. Petersburg, RNIITO im. R.R. Vredena, 2008, 301 p.

4. Hardinge K. The direct lateral approach to the hip. The Journal of Bone and Joint Surgery, 1982; vol. 64 B, pp. 17-19, doi 10.1302/0301-620x.64b1.7068713.

5. Leonova S.N., Grishchuk A.N. New method of surgical access to the hip joint in endoprosthesis [Novyi sposob khirurgicheskogo dostupa k tazobedrennomu sustavu pri endoprotezirovanii]. Vrachaspirant - Postgraduate doctor, 2017, vol. 82, no. 3, pp. 109-118.

6. Harris W.H. Traumatic arthritis of the hip after dislocation and acetabular fractures: treatment by mold arthroplasty. An end-result study using a new method of result evaluation. The Journal of Bone and Joint Surgery, 1970, vol. 51, no 4, pp. 737-755, doi 10.2106/00004623-196951040-00012. 